\title{
RELAÇÕES CONJUGAIS E FAMILIARES NA PERSPECTIVA DE MULHERES DE DUAS GERAÇÕES: "Que SEJA TERNO ENQUANTO DURE"
}

\author{
Sabrine Mantuan dos Santos Coutinho* \\ Paulo Rogério Meira Menandro**
}

\section{ResUmo}

Este relato é um recorte de extensa pesquisa que buscou identificar a rede de representações sociais (RS) estabelecida em torno do ser mulher na família. Centra-se na questão da conjugalidade e busca verificar se a vivência conjugal e familiar sofreu modificações significativas num intervalo de aproximadamente 3 décadas. Foram realizadas 20 entrevistas narrativas, semiestruturadas, com mulheres de estrato socioeconômico médio e baixo: 10 que tiveram filhos nos anos 1960 (1 a geração) e 10 nos anos 1990 (2a geração), filhas das primeiras. A entrevista permitiu às participantes falarem de suas experiências e práticas cotidianas em relação aos contextos familiar e conjugal. Visando agregar procedimentos complementares, os dados foram organizados/analisados a partir de adaptação do método fenomenológico para investigação psicológica e do software Alceste.

Os resultados evidenciaram tanto continuidades quanto rupturas entre as gerações, podendo ser destacadas mudanças expressivas de uma geração à outra em relação a importantes aspectos do relacionamento conjugal como: a manutenção do casamento que deixa de ser o objetivo principal; as relaçóes conjugais, de forma geral, tornam-se mais abertas; há redução de interdições em relação à mulher; e o investimento feminino no casamento passa a dividir espaço com o maior envolvimento masculino.

Palavras-chave: relações conjugais; família; representações sociais; gênero; pesquisa intergeracional.

* Doutora em Psicologia, coordenadora e Professora do Curso de Psicologia da Faculdade do Espírito Santo - UNES, Pós-doutoranda no Programa de Pós-Graduação em Psicologia da Universidade Federal do Espírito Santo - UFES.

** Doutor em Psicologia, Professor Adjunto da Universidade Federal do Espírito Santo, no Departamento de Psicologia Social e do Desenvolvimento, professor do Programa de PósGraduação em Psicologia da Universidade Federal do Espírito Santo - UFES. 


\begin{abstract}
CONJUGAL AND FAMILIAL RELATIONS IN THE PERSPECTIVE OF TWO GENERATIONS OF WOMEN: "BUT BE ENDEARING WHILE IT LASTS"

This report is an extract of an extensive research which attempted to identify the social representation (SR) net established around being a woman in the family. It is centered on the conjugality question, attempting to verify if the conjugal and familial living experience suffered significant modifications after a period of approximately three decades, considering women of the same family, but from different generations. Twenty semi-structured narrative interviews were taken with women of low or medium social-economic strata: ten who had children during the 1960 decade ( $1^{\text {st }}$ generation), and 10 who had children during the nineties ( $2^{\text {nd }}$ generation), daughters of the first group. The interview allowed the participants to talk about their quotidian experiences and practices with respect to familial and conjugal contexts. In order to aggregate complementary procedures, the data were organized/analyzed using an adaptation of the phenomenological method for psychological investigation, and the Alceste software. The results pointed both continuities and ruptures between generations, expressive changes from one generation to the other being marked with respect to important aspects of the conjugal relationship. For example: the maintenance of the marriage ceases to be the main objective; the conjugal relations, in general, become more open; there is a reduction of the interdictions towards women; the feminine investment on the marriage now shares space with increased male interest.
\end{abstract}

Keywords: conjugal relations; family; social representations; gender; intergenerational research.

\title{
INTRODUÇÃO
}

Este relato se ocupa de parte dos dados obtidos em pesquisa sobre a rede de representaçôes sociais (RS) estabelecida em torno do ser mulher na família e sobre práticas femininas cotidianas a partir do relato de mulheres de duas gerações (mães e filhas). Também foi intuito do referido trabalho captar transformações e continuidades nas RS e práticas dessas mulheres, considerando sua inter-relação com as mudanças na esfera familiar e conjugal nas últimas cinco décadas.

Serão apresentados e discutidos resultados relacionados ao cotidiano conjugal e familiar destas mulheres, sem considerar os dados associados às questōes peculiares da experiência de maternidade. Trata-se de empreendimento arriscado, pois vivências do casamento, da maternidade e de gênero estão diretamente interrelacionadas, umas determinando as outras, sendo difícil sua separação.

Apesar de muitas vezes concebida como instituição natural, a família nem sempre teve a configuração atual. Sua constituição histórico-social foi negligenciada por décadas, o que permitiu que o formato da família nuclear, marcado pelo nú- 
mero reduzido de membros, pela intimidade e afetividade, viesse a ser considerado modelo universal.

Costa (1999), já no final dos anos noventa, ao estudar a relação entre a instauração da ordem médica e o processo de constituição da família nuclear, revê como essa instituição e as relações intrafamiliares se configuraram ao longo da história - além de destacar o processo de normatização e de tutela da família, posto em ação com o movimento higienista. Foi imposta uma revolução de costumes e práticas prescrevendo: o amor entre pais e filhos, a privacidade do lar, além de uma "educação física, moral, intelectual e sexual inspirada nos preceitos sanitários da época” (Costa, 1999: 12).

Quintas (2000) diz que a família só mereceu interesse científico na segunda metade do século XIX, quando passou a ser vista como instituição social e histórica e não como fruto exclusivo de determinação biológica. Os estudos sobre família avançaram e, atualmente, no Brasil, há muitos em que esse tema é destaque. Alguns exemplos: Assmar, Ferreira, Novaes e Tomaz (2000); Benincá e Gomes (1998); Brasileiro, Jablonski e Féres-Carneiro (2002); Costa (1999); Coutinho (2008); Dias e Lopes (2003); Falcke e Wagner (2005); Féres-Carneiro (2001); Grzybowski (2002); Jablonski (1998); Lins de Barros (2006); Lisboa, Féres-Carneiro e Jablonski (2007); Quintas (2000); Rêgo, Bastos e Alcântara (2002); Relvas (2002); RochaCoutinho (1994, 2003, 2006); Vaitsman (1994), Vitale (2002).

No contexto de aceleradas transformaçōes culturais em que valores tradicionais e modernos coexistem, a instituição familiar tem sido palco de modificações concomitantes às amplas mudanças decorrentes do processo de modernização. Nader (2001) assinala diversos fatores que dificultaram a manutenção do modelo tradicional, composto por casal e filhos: intensificação da pobreza; entrada da mulher no mercado de trabalho; laços familiares afrouxados pela instabilidade conjugal; institucionalização do divórcio em 1977, entre outros.

Jablonski (1998), ainda no final dos anos noventa, já dizia que não apenas a família nuclear urbana vem perdendo espaço, mas a própria instituição do casamento não pode ser pensada independentemente da primeira. Sem dúvida, as transformações socioeconômico-culturais das últimas décadas do século $\mathrm{XX}$ mudaram a forma como homens e mulheres pensam o casamento e a vida familiar - o casamento tradicional figura apenas como uma alternativa entre tantas outras possíveis, o que revela um novo cenário.

Hoje, sem ter como função primordial atender interesses econômicos e políticos, o que o caracterizou por séculos (Ariès, 1981; Giddens, 1992), o casamento é também movido por razões afetivas e sexuais, sendo experienciado de múltiplas formas. Diante das novas expectativas femininas e masculinas de realização pessoal, 
profissional e afetiva, emergem configurações de união que antes não eram vistas, cresce o número de separações e o de uniōes consensuais. $\mathrm{O}$ "até que a morte nos separe" vem sendo substituído pelo "que seja eterno enquanto dure". Talvez valha dizer, embora seja menos romântico, que já seria bastante que se cumprisse a expressão "que seja terno enquanto dure".

Mesmo com as transformações socioculturais que viabilizaram maior igualdade nas relações familiares e conjugais, acompanhando transformações no papel da mulher na família e na sociedade (Unbehaum, 2001), ainda é difícil romper com valores tradicionais - dentre os quais estão as diferenças de gênero instituídas, escapar da contradição entre moderno e tradicional, principalmente quando os mesmos são reforçados a todo tempo por discursos religiosos, pedagógicos e psicológicos, que insistem em ver o casamento e a constituição de família como as principais metas "femininas". Assim, buscou-se verificar se a vivência conjugal e familiar sofreu modificaçōes significativas num intervalo de cerca de três décadas, objetivando compreender como mulheres de uma mesma família, mas de gerações diferentes (díades mães-filhas), vivenciaram essas relações.

No decorrer da história foi produzido conhecimento acerca do que é ser mulher, que não se restringia à esfera científica, mas era integrado ao senso comum, permitindo a qualquer pessoa compreender a realidade e dar significado a comportamentos e atitudes considerados importantes para seu contexto de vida. Esse conhecimento, socialmente estabelecido, transmitido de geração a geração, a partir das experiências cotidianas, da memória social e das instituições sociais, é aceito e não deixa brecha para dúvidas, como destaca Marcová (2006). Tal conhecimento começa a receber ênfase com o conceito de RS proposto por Serge Moscovici (1978).

Para Moscovici (1978), os processos cognitivos e afetivos estão na base da compreensão da realidade e integrados ao meio social que é próprio da realidade dos grupos humanos. Eles contribuem, em parte, para a configuração desse meio social e constituem-se, em parte, sob sua influência (o que diverge de perspectivas nas quais se considera a existência de um cenário de natureza social, que funciona apenas como ambiente em que diversos processos se desenrolam, sem qualquer interdependência ambiente-processos). Assim, a proposta moscoviciana não pressupõe dicotomia entre psicológico e social, caracterizando-se como psicossociológica.

Segundo Moscovici (1978: 27), a RS consiste numa "modalidade de conhecimento particular que tem por função a elaboração de comportamentos e a comunicação entre indivíduos". Caracteriza "um corpus organizado de conhecimento e uma das atividades psíquicas graças às quais os homens tornam inteligível a realidade física e social, inserem-se num grupo ou numa ligação cotidiana de 
trocas e liberam os poderes de sua imaginação" (Moscovici, 1978: 28).

Jodelet (2001: 22) também destaca a importância das RS no cotidiano dos indivíduos, conceituando-as como "uma forma de conhecimento, socialmente elaborada e partilhada, com um objetivo prático, que contribui para a construção de uma realidade comum a um conjunto social".

As RS têm caráter dinâmico, como enfatiza Queiroz (2002: 94): "é no processo de significação que os sujeitos, na sua relação com o mundo, reconstroem novos significados e são recriados por estes”. Portanto, as RS constituem um processo. Dependem tanto de fatores circunstanciais quanto de fatores mais globais, que vão além da situação em si mesma, como aponta Abric (2000).

As RS não ditam as ações dos indivíduos, apenas funcionam como orientadores para a ação, ou seja, definem as possíveis condições da ação (Rouquette, 2000). Logo, nessa relação os indivíduos têm papel ativo. Além disso, RS e práticas sociais estão ligadas dialeticamente e não por dependência causal, influenciando-se mutuamente, embora essas influências não sejam da mesma modalidade. As RS atuam como guia para as práticas, e estas como agentes na mudança das RS e não apenas como reflexo das mesmas.

\section{Trajeto metodológico PerCorrido}

O grupo de participantes foi constituído adotando-se um critério principal: mulheres que tiveram filhos na década de 1960 (1ª geração), cada qual com pelo menos uma filha que tivera filhos na década de 1990 (2a geração).

Na seleção das participantes da $1^{\text {a }}$ geração foi composto um grupo diversificado de forma a garantir que condições possíveis de serem variáveis interferentes em relação às suas RS e práticas estivessem presentes: incluir mulheres que exerceram trabalho remunerado fora de casa após o casamento, assim como mulheres que não trabalharam fora no mesmo período; e garantir que entre elas figurassem algumas mulheres que tivessem vivido separação conjugal na época em que tinham os filhos pequenos (situação infrequente na época). Para a constituição do grupo da $2^{a}$ geração (as filhas), a exigência foi apenas serem casadas (legalmente ou não) e terem sido mães nos anos 1990 .

Foram realizadas 20 entrevistas individuais, semiestruturadas, com mulheres de estrato socioeconômico de média para baixa renda na época do casamento: 10 que tiveram filhos na década de 1960 e 10 que os tiveram na década de 1990 (filhas das primeiras). As entrevistas apoiaram-se em roteiro cujas questôes lhes facultavam falar de suas experiências e práticas conjugais e familiares. 
Transcritas as entrevistas, os dados foram organizados a partir da apreensão das unidades de significado presentes nos discursos, visando desvendar a estrutura do fenômeno experienciado. Tal forma de organizar / apresentar os dados baseou-se em Trindade (1991), que trabalhou com o modelo desenvolvido por Bullington e Karlsson (1984) a partir do método fenomenológico para investigação psicológica. Esse método propõe a busca da experiência "tal qual foi ou é vivenciada" (Trindade, Menandro \& Gianórdoli-Nascimento, 2007: 78) pelo indivíduo, ou seja, o significado de determinado fenômeno a partir das descrições e explicações das experiências fornecidas pelo próprio indivíduo.

Com base em Trindade (1991), os dados individuais foram organizados em procedimento de quatro fases: após transcrição das entrevistas e leitura/análise das mesmas com base nos objetivos do estudo, foram identificadas unidades de significado; a seguir, as falas das participantes foram incluídas nessas unidades; na próxima fase as unidades de significado foram convertidas da linguagem dos participantes para uma linguagem parcialmente padronizada, considerando os significados e a transcrição de algumas falas importantes para exemplificar a questão sob foco; por fim, as unidades de significado foram transformadas em uma estrutura, articulando os constituintes significativos obtidos nas respostas dos participantes e possibilitando sua apreensão mais integrada.

Para enriquecer e complementar a análise dos dados utilizou-se, ainda, uma técnica de análise estatística de texto, o software Alceste. Este foi desenvolvido por Reinert (1990), adequado à análise de dados provenientes de entrevistas e empregado em vários estudos no campo das RS, já que possibilita a apreensão do conteúdo das RS e a identificação de seu campo comum (Menandro, 2004).

$\mathrm{O}$ Alceste distingue "classes de palavras que representam diferentes formas de discurso a respeito do tópico de interesse” (Kronberger \& Wagner, 2002: 427). Analisa coocorrências localizadas de palavras, sem, evidentemente, interpretar sentido e contexto das sentenças, embora resulte em dados organizados de forma que tem grande valor heurístico para o processo interpretativo. Uma das vantagens da técnica é que em um curto período de tempo o pesquisador tem uma visão geral do volumoso corpus de dados (Kronberger \& Wagner, 2002).

O software reconhece as unidades de contexto iniciais (UCI), constituídas pelas próprias entrevistas, gerando a seguir segmentos de texto (unidades de contexto elementar - UCE) que são sentenças dimensionadas pelo programa de acordo com o tamanho de cada UCI e sua pontuação. Como passo seguinte agrupa palavras que coocorrem, considerando seus radicais (conforme registro em dicionário que integra o programa), e efetua o cálculo das suas respectivas frequências. Feito isso, o programa executa uma série de cálculos, cruzando os segmentos de 
texto de modo a conseguir classes de UCE que compartilhem seus vocabulários, ao mesmo tempo que se diferenciam dos outros conjuntos de UCE, resultando uma hierarquia de classes apresentada em modelo de árvore, ou seja, em dendrograma (Teixeira, Schulze \& Camargo, 2002).

Com base no delineamento das estruturas individuais e do processamento do Alceste, foi possível uma discussão dos dados completos, considerando três eixos de análise estabelecidos a partir dos objetivos do trabalho. No presente relato são abordados os resultados provenientes da análise das estruturas e do Alceste referentes ao eixo que trata da vivência conjugal e familiar.

\section{Resultados E Discussôes}

\section{CONHECENDO AS PARTICIPANTES}

Para facilitar a compreensão dos leitores e garantir o anonimato das participantes, foram utilizados nomes fictícios. As mulheres de uma mesma família ( $1^{\mathrm{a}}$ e 2a geração) são identificadas por nomes iniciados pela mesma letra e aparecem em sequência no Quadro 1 (ver anexo).

A idade das participantes da $1^{\text {a }}$ geração variou entre 60 e 74 anos, com média de 64,6 anos. Na 2a geração, a idade variou entre 34 e 45 anos, com média de 39 anos. Entre as mulheres da $1^{\mathrm{a}}$ geração, sete não concluíram o $1^{\circ}$ grau, quatro tendo cursado apenas o primário. Duas concluíram o $2^{\circ}$ grau e apenas uma cursou o $3^{\circ}$ grau. Na $2^{\mathrm{a}}$ geração, sete cursaram o $3^{\circ}$ grau (cinco o concluíram, uma está em curso e uma não o completou) e três concluíram o $2^{\circ}$ grau.

Quanto ao estado civil, na $1^{a}$ geração são três viúvas, duas divorciadas e cinco casadas. Todas as mulheres da $2^{\text {a }}$ geração são casadas. $\mathrm{O}$ tempo de união das mulheres da $1^{\text {a }}$ geração que permaneceram casadas variou de 40 a 53 anos (média de 45). As duas participantes divorciadas ficaram casadas por 13 e 15 anos. O tempo de união na $2^{\text {a }}$ geração variou de 12 a 20 anos (média de 15,5).

Sobre atividade profissional após o casamento, na $1^{\text {a }}$ geração só três mulheres trabalharam fora, sendo as demais responsáveis por cuidar dos filhos e da casa (em dois casos, também costuravam em casa). As mulheres que se separaram assumiram atividades como costura e bordado para ajudar no sustento dos filhos. Na geração mais jovem, nove participantes trabalharam fora após o casamento.

Cinco participantes da $1^{\text {a }}$ geração pertenciam à classe popular quando tinham os filhos pequenos e cinco à classe média. Todas as participantes da $2^{\text {a }}$ geração são de classe média. 
Bassanezi (2002) e Del Priore (2005) apontam que, em meados do século XX, o casamento permanecia como objetivo primeiro das mulheres. Os discursos das participantes da $1^{\text {a }}$ geração são categóricos nesse sentido, como podemos perceber nos exemplos a seguir: "Todas as moças da minha época a função delas era o casamento. [...] O casamento era uma estabilidade para a mulher, porque geralmente a mulher não tinha profissão, tinha que viver submissa ao marido" (Berenice); "Naquele tempo todo mundo casava novo, ninguém tinha esse interesse como tem hoje, a gente só pensava em casar, que se não casasse o pessoal ficava falando que a gente era solteirona, essas coisas" (Fátima).

O temor das moças era não se casar, pois não teriam cumprido o "destino feminino" e sofreriam com esse estigma. "Uma mulher com mais de 20 anos de idade sem a perspectiva de um casamento corria o risco de ser vista como encalha$d a$, candidata a ficar pra titia. Aos 25 anos, considerada solteirona, já era fonte de constrangimento" (Bassanezi, 2002: 619).

Para as participantes do presente estudo, a possibilidade de prosseguir com os estudos antes do casamento se concretizou apenas para Célia, pertencente à classe média à época (concluiu o magistério). Sete participantes sequer concluíram o $1^{\circ}$ grau. Após o casamento, só Glória e Ivone puderam continuar o processo de escolarização, uma concluindo o $2^{\circ}$ grau e a outra o nível superior.

A pouca expressividade do trabalho feminino fora de casa, em meados do século XX, (considerada a classe média) fica evidenciada. Na $1^{\text {a }}$ geração só três mulheres trabalharam quando os filhos eram pequenos, duas delas em atividades com certa flexibilidade de horário e apenas uma com emprego formal de maior carga horária. Na época, a maioria das mulheres dedicava-se aos filhos e ao lar. $\mathrm{O}$ trabalho fora de casa era alvo de preconceito, e os homens impediam a participação de suas filhas e esposas em funções extradomésticas.

Os resultados processados pelo Alceste confirmam a importância e a centralidade do casamento para as mulheres naquela época, conforme se pode observar nas classes 2 e 5 (intimamente associadas) do dendrograma das classes da $1^{\text {a }}$ geração (Figura 1; ver anexo), nas quais o casamento ocupa lugar central entre os conteúdos, e aparece como projeto de vida feminino.

Percebe-se que, nesse grupo, a construção da identidade feminina passa, necessariamente, pelo ideal do casamento e da vida privada em um lar próprio. Contudo, isso não quer dizer que o discurso sobre o casamento seja homogêneo entre essas mulheres. As classes identificadas a partir do Alceste conjugam oposições/ antinomias que atuam engendrando RS e nos possibilitam compreender a dinâmi- 
ca do discurso das participantes. Essas classes, interpretadas como representação, constituem um sistema articulado que só pode ser compreendido em conjunto. Considerar tal configuração mais ampla da representação não implica desconsiderar os conteúdos das classes individuais; ao contrário, a análise destas acaba sendo muito reveladora e favorece a compreensão do campo da representação.

Os dados indicam que foi construída uma rede de significações em torno do ser mulher na família, na qual um dos elementos centrais é o casamento (o que não significa que seja o único ou o mais importante). Há um conhecimento socialmente partilhado sobre o que casamento representa, sobre como deve e como não deve ser, que exerce evidente função na dinâmica social. Assim, a condição de ser mulher parece estar ancorada no casamento.

Mesmo com as mudanças sociais que começaram apenas a se esboçar nos anos 1950, impulsionadas, sobretudo pelos processos de urbanização e modernização, o casamento nessa época ainda figurava como "destino inevitável", do qual as moças de família não poderiam escapar. Mesmo que nem todas as mulheres se rendessem a tal "sina", a RS do casamento como realização feminina - presente, inclusive, na imprensa da época, como destaca Bassanezi (2002) - orientava comportamentos da sociedade, definindo o que era apropriado ou não para as mulheres.

$\mathrm{O}$ fato de o casamento ser muito valorizado não significa que fosse objeto de discussão em todos os aspectos, como se observa nas entrevistas da investigação que aqui se descreve. Algumas participantes (Dalva, Eva, Fátima) revelaram que questões relativas à atividade sexual, por exemplo, não eram comentadas entre as moças ou ensinadas por suas mães. Aprendiam apenas que deveriam cuidar da casa, dos filhos e agradar o marido. Essa censura, ou reserva, ou silêncio, visava manter a reputação e pureza das moças, porém a desinformação e o desconhecimento tornavam a iniciação sexual feminina (mesmo no casamento) um momento pouco tranquilo (Bassanezi, 2002).

Muitas mulheres viam no casamento a possibilidade de se libertarem da opressão dos pais. A educação era rígida e as mulheres eram controladas por rédeas curtas. Mais da metade das participantes mencionou o controle e rigor dos pais na educação. Moças não podiam sair, exceto com a companhia de um responsável; também não podiam ficar a sós com um homem, principalmente o namorado. Tinham que se preservar e não dar motivos para ficarem mal faladas, para conseguirem chegar ao casamento. A fala que se segue exemplifica a força da repressão assumida como autorrepressão, que inclui até mesmo elementos conspiratórios: "Eu mesma pensava assim, sempre pensei, eu não vou dá confiança a esse rapaz não porque depois ele fala com os colegas dele... aí depois ninguém vai querer me namorar. Eu pensava isso, isso não saía da minha cabeça” (Ana). 
Bassanezi (2002) destaca que nos anos cinquenta havia um código da moralidade conhecido por todos, portanto "todos" (pais, vizinhos, amigas, educadores, entre outros) estavam aptos a julgar o comportamento das moças. Para garantir boa reputação, a moça deveria: evitar roupas ousadas; evitar sair sozinha com um rapaz e ficar em lugares escuros ou em situação que sugerisse intimidade; e evitar a fama de namoradeira e garota "fácil". Mesmo que o casamento já fosse certo e estivesse próximo, deveriam ser evitadas certas situações com o namorado para garantir a reputação (leia-se, a virgindade). Os rótulos mãe solteira e mulher fácil, praticamente sinônimos na época, deveriam ser evitados.

Zechlinski (2006) destaca que:

Em meados do século XX a manifestação da sexualidade feminina continuava sendo considerada um perigo: recato sexual era um selo de garantia de uma mulher honrada e pura. Já aos rapazes, a moral social permitia experiências sexuais antes do casamento e com várias mulheres, pois o homem tinha essas necessidades naturais. Dessa forma, enquanto havia uma restrição da sexualidade feminina aos parâmetros do casamento convencional, as experiências sexuais masculinas eram amplamente favorecidas e aceitas (Zechlinski, 2006: 28).

Essa concepção ainda é tão forte para uma participante (Fátima), a ponto de ela dizer que a grande decepção de sua vida foi o fato de a filha mais velha ter se tornado "mãe solteira", tendo até vergonha de sair na rua por causa disso. Outra participante (Ana) menciona que avisava às filhas - e hoje o faz às netas - que não aceita de forma alguma que tenham filhos fora do casamento.

Os namoros, na $1^{\text {a }}$ geração, iniciaram-se, em geral, em locais públicos (praças, festas), onde moças e rapazes circulavam visando, de certa forma, encontrar pretendentes que deveriam ser aprovados pelos pais, sendo que uma escolha desaprovada resultava em ruptura. No caso de namoro firmado, os pais estabeleciam hora e dia para namorar. Os namoros não eram muito longos, envolviam pouco contato físico, e o casal não podia ficar sozinho. O clima era marcado, muitas vezes, por grande ansiedade, como ressalta uma participante que chegava a "passar mal" no dia de namorar.

Sobre expectativas em relação ao casamento, as participantes ressaltaram aspectos bem objetivos como ter uma casa e cuidar da casa, do marido e dos filhos, coisas que, certamente, aprendiam desde pequenas. Também enfatizaram ter uma vida boa junto ao marido, sem muitas dificuldades, com mais liberdade, e a ideia do casamento para sempre.

As expectativas de algumas participantes em relação ao casamento não foram todas alcançadas (é a avaliação que fazem hoje). Destaca-se a entrevistada Berenice 
que afirma que hoje não se casaria, pois sua experiência foi muito negativa: "Se fosse hoje em dia pra eu casar eu não casaria... eu ia ter meus filhos independente. Eu ia procurar estudar, ter um emprego onde eu pudesse manter os meus filhos, mas eu ia cuidar deles sozinha, sem homem". Glória enfatiza que seu casamento foi um erro, pois havia muita briga, incompreensão e ciúme por parte do marido. Assim que os filhos se tornaram adultos, saiu de casa para viver com outro homem. É a única participante que tomou a iniciativa da separação (ficou viúva logo em seguida). Hilda deixa "escapar" que o casamento não foi totalmente como esperava e o marido não foi como imaginava, mas deu para "segurar as pontas".

Metade das participantes do grupo (Ana, Eva, Fátima, Hilda e Joana) viveu infidelidade conjugal. Hilda e Joana apenas sugerem a traição, mas as filhas a confirmam. Hilda afirma que o marido "aprontou" por ser muito novo e não estar preparado como ela. Joana percebe a traição como algo a ser relevado pela mulher para que o casal se mantenha, em acordo com o pensamento socialmente valorizado na época.

Del Priore (2005: 294) diz que nos anos cinquenta as mulheres tinham que se fazer de "cegas, surdas e mudas" diante dos deslizes do marido para manter o casamento e não incitar ainda mais o interesse do marido por outras mulheres. A separação era "a grande ameaça que pairava sobre as esposas" naquele período: "Maridos não deviam ser incomodados com suspeitas, interrogatórios ou ciúmes por suas esposas. Permitir que eles saíssem com amigos, relevar suas conquistas amorosas e aventuras e atraí-los com afeição eram procedimentos aconselhados para quem quisesse manter uma boa vida conjugal” (Del Priore, 2005: 294).

Bassanezi (2002) aborda o tema e lembra que, além da questão afetiva e das necessidades financeiras, havia preconceito em relação às mulheres separadas. Assim, a realização da mulher dependia do casamento, que deveria ser mantido a qualquer custo. Uma boa esposa não incomodaria o marido com questões do dia-a-dia, vistas como de menor importância, nem deveria queixar-se ou reclamar atenção, muito menos falar de suas insatisfações. Caso o fizesse, estaria estimulando o marido a buscar tranquilidade e felicidade fora de casa. As revistas da época davam todas as dicas de como a boa esposa deveria se comportar para manter a "felicidade conjugal", desestimulando os protestos e incitando o uso de estratégias sutis - "o jeitinho feminino".

Os maridos de Eva e de Fátima deixaram a família por causa de outra mulher, quando os filhos ainda eram pequenos. Fátima, mesmo sabendo do relacionamento extraconjugal do marido, ficou casada por mais de sete anos. Nunca propôs a separação e por ela teria continuado daquele jeito, até o fim. Ambas destacam o 
preconceito contra a mulher separada - vista na época como má influência, como liberada, alguém que não soube cumprir bem seu papel de esposa.

Chama a atenção o caso de Ana, casada há mais de 50 anos e que sabe há muito tempo o marido mantém relacionamento com outra há mais de três décadas. Sabe que o marido frequenta diariamente a casa da outra mulher, tem filhos com ela, mas não aceita a separação (assim como ele). Atribui a traição a "tal" mulher que "foi atrás dele", ou seja, ele "não teve culpa", apenas "não resistiu" à tentação, o que se deve à natureza do homem. A revolta da participante é com a outra mulher, a amante, e não com o marido. Como ressalta Bassanezi (2002: 635), "a infidelidade masculina justificava-se pelo temperamento poligâmico dos homens - um fator natural que, mesmo quando considerado uma fraqueza, merecia a condescendência social e a compreensão das mulheres".

A maioria das participantes avalia positivamente a relação conjugal, em termos gerais, expondo com discrição as dificuldades da vida a dois. É visível a tendência de algumas a relevar dificuldades passadas, como se não valesse a pena ressuscitar determinados "fantasmas" (Hilda e Joana).

Ao compararem a vivência do casamento na época em que casaram com as condições atuais de vida conjugal, as opiniōes se dividiram. Seis avaliam que antigamente era melhor, pois havia mais respeito e amor entre o casal, e a família era mais estruturada. Dizem que hoje as pessoas já se casam pensando na separação, e que a mulher está muito independente, o que não é bom. Também destacam o consumismo e a influência da televisão. As outras quatro acham que atualmente a vivência conjugal é melhor, comporta mais facilidades, pois naquela época a mulher tinha que aguentar muita coisa para permanecer casada, por não ter como sustentar a si e aos filhos. Destacam que hoje as mulheres trabalham fora, conquistaram seu espaço e têm uma cabeça mais aberta.

Os dados mostram que as participantes desse grupo, quando jovens, compreendiam o casamento como única opção para a mulher, como realização feminina, o que não significa que representasse o caminho mais fácil. Apesar de nos anos cinquenta começarem a se desenhar possibilidades de novos papéis para as mulheres na família e na sociedade, percebe-se que a RS das participantes sobre o casamento está ancorada em circunstâncias histórico-sociais anteriores, que definiram diferenciações de gênero por meio de processos de normatização. Mesmo afirmando que não pensavam ou discutiam sobre como seria o casamento (caso de muitas), ressaltam que a importância do mesmo para a definição da identidade feminina era inquestionável.

Ao longo dos séculos, em virtude de interesses diversos, principalmente aqueles relacionados à transmissão da propriedade, a instituição do casamento 
consolidou-se legalmente em inúmeras sociedades, e foram definidos os comportamentos apropriados para homens e mulheres no âmbito da relação conjugal. Nesse sentido, essa ideia do casamento como única saída apresentada pelas participantes está ancorada em concepções cuja determinação obedece aos fatores condicionantes socioculturais. Estes se articularam no decorrer da história e também contribuíram para engendrar significações próprias para a condição feminina.

\section{O CASAMENTO PARA A $2^{a}$ GERAÇÃO DE MULHERES}

As participantes desse grupo viveram sua juventude principalmente nos anos oitenta. Nessa época, como fruto das discussões inauguradas, sobretudo com os movimentos feministas, já não havia um discurso uníssono acerca do papel da mulher na família e na sociedade. Coexistiam ideias que de um lado apregoavam novas possibilidades para a mulher além da vida doméstica, por outro valorizavam o papel feminino tradicional (voltado para o casamento e a maternidade). Não obstante, constatou-se que, para a maioria das participantes dessa geração, o casamento ainda era um dos projetos para a vida. Mesmo as que planejavam seguir carreira profissional e se estabilizar financeiramente para depois casar ressaltaram o casamento como projeto pessoal. Constatou-se em algumas participantes certo temor de não casar, de o casamento não dar certo, ou de "não darem conta do recado".

Jablonski (2001) propõe que as pressões sociais para o casamento, embora menos evidentes em nossos dias, afetam principalmente as mulheres. "Uma mulher que chegue aos 40 anos sem nunca ter se casado ou se unido maritalmente a alguém será vista com reservas, desconfiança, podendo vir a sofrer algum tipo de discriminação" (Jablonski, 2001: 83). Mesmo com a disseminação de novas expectativas femininas (e masculinas) de realização pessoal, o casamento ainda é opção de peso para a mulher, o que possibilita a manutenção de configurações tradicionais em se tratando de vida familiar.

É preciso considerar também que o casamento não é mais visto como incompatível com outros projetos femininos (como carreira profissional), sendo possível conciliar várias prioridades. Além disso, um ingrediente valorizado, atualmente, na vida social é a preservação da individualidade, o que tira o casamento da posição de oposição direta a outros projetos pessoais. Araújo e Scalon (2005: 35) dizem que hoje a conjugalidade é norteada pela autonomia, sendo passível de finitude e recomeço, expressando "movimento de busca de relações orientadas por identidades afetivas e sexuais". 
Mesmo valorizando o casamento e tendo "intenção" de continuarem casadas, a separação aparece como possibilidade aceitável para elas, desde que os motivos sejam "justoo" (agressão física, falta de amor, traição, desrespeito). Reconhecem ser comum a separação nos dias atuais, e todas conhecem casos de separação de pessoas próximas. A entrevistada Giovana, inclusive, separou-se do primeiro marido e, ainda assim, mencionou que o preconceito contra a mulher separada permanece vivo.

A Classe 2 do dendrograma de classes da $2^{\text {a }}$ geração (Figura 2; ver anexo) agrupa conteúdos que mostram que casamento e constituição de família integram seus projetos de vida, mas, ao mesmo tempo, a separação é vista como uma possibilidade concreta. Portanto, o casamento continua sendo um dos projetos, mas existe a possibilidade de ruptura do relacionamento conjugal sem grande rejeição social. A constituição de família e o casamento estão incluídos nos planos femininos, o que não significa que sejam o projeto, nem que sejam idealizados como mil maravilhas, sem receios e inseguranças.

As participantes desse grupo se casaram jovens. Para a maioria, está em vigência uma ideia bastante romantizada do casamento e do cônjuge: casar por amor, com o grande amor de sua vida. Também está presente a ideia do casamento como obra divina. O medo de ficar solteira deixou de ser o grande motivador do casamento, que, então, passou a ser localizado em um contexto basicamente afetivo/sentimental, como propôs Jablonski (1998), no final da década de noventa.

Enquanto na $1^{\text {a }}$ geração o namoro exigia o consentimento dos pais, que interferiam na escolha do marido (de forma determinante, na maioria das vezes), tal aspecto perde importância no segundo grupo. Ainda assim, Clara explicita a reprovação de sua mãe em relação à escolha de seu marido, o que perdurou por muitos anos após o casamento. Julia, por sua vez, destaca a pressão existente em sua família para que as filhas se casassem jovens, pois os pais não aceitavam namoros longos e nem que namorassem e estudassem ao mesmo tempo (não viam possibilidades de conciliação).

Quanto ao namoro, de forma geral, não havia tantas restrições, ou estas eram menos explícitas. Apenas duas participantes deixam claro o controle dos pais. Contudo, percebe-se nesse grupo a importância da religião para a manutenção de valores e papéis tradicionais. No caso das evangélicas (metade das participantes) isso fica ainda mais evidente, pois ressaltam a importância dos ensinamentos recebidos na igreja em relação ao namoro e casamento (por exemplo: preservação da virgindade até o casamento; escolha do pretendente entre membros da igreja).

Nessa geração, o casamento era assunto frequente nas conversas com amigas e com parentes e era um ideal compartilhado pela maioria. Apenas uma partici- 
pante afirmou que não tratava muito do assunto por ter outros planos além do casamento. As expectativas eram positivas e bastante romantizadas, e em alguns casos os relatos mostram que não foram totalmente concretizadas. De fato, a sociedade contemporânea contribui para a criação de expectativas conjugais difíceis de alcançar. A esse respeito Jablonski (1998: 85) destaca que, "ao tornar sinônimos amor e casamento, este ainda visto pela maioria das pessoas como indissolúvel e monogâmico, a cultura, ela própria, cria uma armadilha inescapável para os jovens nubentes, gerando uma expectativa que não poderá se cumprir”.

Bárbara e Elisa destoam do grupo ao apresentarem expectativas menos romantizadas e mais realistas: "Como eu nunca procurei um príncipe encantado... como eu nunca tive expectativa de nada muito perfeito e sem problemas, não tive decepçōes nesse sentido" (Bárbara); “Às vezes eu tinha até assim, um pé atrás no casamento... nunca tive aquela coisa de ilusão, eu tinha pé no chão” (Elisa).

Todas as participantes afirmaram que o casamento não atrapalhou outros projetos; as mudanças dele decorrentes não são vistas como interferências. Mudar de cidade em função do trabalho do marido, não ter dado prosseguido com os estudos, ter pulado uma etapa da vida são fatos mencionados como determinados pelo casamento, mas não como prejuízos. Continuar trabalhando e estudando após o casamento, com aprovação e incentivo do marido, é citado por algumas mulheres do grupo como exemplo de que foi possível conciliar o casamento com outros projetos pessoais.

Uma das classes do dendrograma da $2^{a}$ geração (classe 3) indica as dificuldades encontradas no início da vida familiar/conjugal e, ao mesmo tempo, as possibilidades de lidar com tais desventuras. Isso sugere que as participantes dessa geração compreendem a vida conjugal e familiar sem aspectos muito idealizados, característicos da geração mais velha.

Ao avaliarem a vida conjugal, as mulheres da $2^{\text {a }}$ geração falam com mais tranquilidade sobre suas dificuldades. Contudo, é visível a tendência a ressaltar os aspectos positivos (companheirismo, constituição de família, fazer planos juntos) e a constante minimização dos aspectos negativos (dificuldades financeiras, as concessões constantes, a renúncia aos desejos pessoais). Amor e companheirismo são vistos como aspectos essenciais para lidar com as adversidades da vida conjugal.

As entrevistadas mencionaram semelhanças e diferenças entre seus casamentos e os de seus pais. Cinco enfatizaram similaridades (citando alguns pontos de divergência) e destacaram buscar casamento bastante distinto daquele vivido por seus pais. A principal diferença mencionada por seis delas é o fato de trabalharem (o que suas mães não faziam), atividade essa que Barbosa e Rocha-Coutinho (2007) destacam como um dos aspectos que diferenciam a geração atual das anteriores. 
Realização profissional e sucesso pessoal tornaram-se objetivos femininos, fazendo com que muitas mulheres posterguem ou ignorem projetos tradicionalmente vinculados às mulheres: casar e ser mãe. Uma das classes resultantes do processamento pelo programa Alceste (classe 4) foi alimentada basicamente pelas participantes que trabalhavam fora quando os filhos eram pequenos, sugerindo que a entrada da mulher no mundo foi onerosa, exigindo articulação das rotinas profissional e familiar. Outras diferenças mencionadas em relação ao casamento dos pais foram atribuídas ao temperamento do pai (muito ciumento, mais calmo, mais expansivo) em comparação com a mãe (mais autoritária, mais brava, mais controladora).

Como semelhança/repetição as participantes apontaram: a submissão da mulher (Alice), a valorização e união da família (Alice, Helena, Diana), a discussão de problemas perto dos filhos (Clara), a dedicação aos filhos (Giovana, Helena), a dificuldade em trocar carinho com o esposo publicamente (Isa), o adultério, a arrogância e a grosseria do marido (Julia).

Ao compararem o casamento, hoje e na época de suas mães, cinco delas consideram as mudanças totalmente positivas; três avaliam que antes era melhor em determinados aspectos: respeito, certa submissão feminina, menos liberdade; uma considera as transformações ora positivas, ora negativas. Note-se a ambiguidade revelada por Isa e Julia: "dizem que hoje é mais fácil porque a mulher deixou de ser submissa”, mas por outro lado acreditam dever haver alguma submissão para que o casamento dê certo. Tal ambiguidade exemplifica confronto entre valores atuais e valores tradicionais e religiosos.

É possível dizer que essa 2a geração compreende o casamento não mais como um destino para o qual não há saídas (ter que casar e permanecer casado até a morte), mas suas RS do casamento estão ancoradas em concepções feministas e igualitárias que emergiram na segunda metade do século XX. Contudo, não descartam a importância do casamento como projeto de vida, apenas não se trata mais de conceber o casamento como o único projeto possível. A despeito disso, o ideal de casamento feliz, baseado no amor, difundido nas sociedades contemporâneas, contrasta com as dificuldades cotidianas e com as incertezas, o que faz com que a vida a dois se dê em meio a ambiguidades e conflitos.

\section{CONTRASTANDO AS GERAÇŌES}

O modo como as participantes compreendem o casamento e a vida familiar resulta da necessidade de entenderem e se relacionarem com a sua realidade. Nesse processo, foi necessário o apoio de conhecimentos e crenças anteriores, visando 
transformar o desconhecido familiar e ancorá-lo numa rede de significações, construindo um sistema explicativo que pudesse orientá-las no dia-a-dia. Suas práticas cotidianas orientam-se por representaçôes interligadas, ou seja, inscritas em um sistema de representações mais amplo, de modo que pode ser mais apropriado falar-se em rede de representaçōes que se organizam em torno do ser mulher na família norteando as práticas sociais e sendo por elas afetadas. Daí a dificuldade de recortar apenas a questão do relacionamento conjugal.

Tal rede de RS constitui referência importante para a formação e sustentação da identidade das participantes, situando-as na realidade social. A forma de as participantes da $1^{\text {a }}$ geração compreenderem e vivenciarem o casamento condiz com o que se esperava da mulher nos anos 50/60. Da mesma forma, as diferenças apresentadas pela $2^{\text {a }}$ geração em relação ao casamento e vida familiar estão diretamente relacionadas aos novos papéis assumidos pela mulher nas últimas décadas. Tal fato evidencia a importância do contexto na produção, manutenção e transformação das RS.

Foram constatados pontos de aproximação e distanciamento entre as gerações estudadas, ou melhor, continuidades e rupturas na forma de entenderem e viverem o relacionamento conjugal. Mesmo que as transformações de uma geração a outra não tenham deslocado completamente o lugar da mulher no âmbito das relações familiares e conjugais, até porque se está falando de um intervalo de poucas décadas, mudanças importantes em relação à vivência do casamento foram verificadas. Ao passo que na $1^{\text {a }}$ geração o casamento representava $a$ alternativa para a mulher, que temia o estigma da solteirona e da separada e, portanto, deveria fazer de tudo para manter a paz e a harmonia conjugal, na $2^{\text {a }}$ geração as participantes, apesar de ainda incluírem o casamento em seus projetos de vida, deixam claro o desejo de vivenciarem um casamento baseado no amor, com diálogo e afeto, sendo a separação uma possibilidade sempre presente. Explicitada direta ou indiretamente nos relatos de várias participantes da $2^{\text {a }}$ geração, a expectativa de construir uma vida conjugal absolutamente diferente do casamento dos pais confirma o surgimento de novos contornos para a relação conjugal.

As expectativas sobre o casamento na $1^{\text {a }}$ geração sempre oscilavam entre ter sua casa para cuidar, constituir família própria, libertar-se da opressão dos pais e ficar casada para sempre. Mesmo que tais expectativas não se confirmassem, cabia à mulher suportar as dificuldades em prol dos filhos e de sua reputação. A regra de manter o casamento a qualquer custo, assumindo nítida posição de submissão, tolerando até traições do marido decorrentes de sua "natureza masculina", perde força entre as gerações, predominando o ideal de liberdade de escolha e de respeito mútuo entre os cônjuges. Isso não significa que situações de infidelidade conjugal 
não mais existam - inclusive a infidelidade feminina. O que muda é a forma como essa situação passa a ser avaliada e vivenciada pelo casal.

Foram identificadas, comparando as gerações, mudanças expressivas no casamento: a preocupação com o risco de perder o marido dá lugar à preocupação de ganhar autonomia e orientar adequadamente o filho - manter o casamento deixa de ser o objetivo principal -; as relaçôes conjugais parecem envolver maior cumplicidade entre os cônjuges; há redução de interdições em relação à mulher; reduz-se a limitação à esfera doméstica e a profissionalização feminina ganha lugar; o investimento feminino no casamento passa a dividir espaço com o maior envolvimento masculino.

A maior escolarização e o trabalho feminino fora de casa constituem importantes mudanças entre os grupos e estão na base de outras modificaçōes substanciais, possibilitando o contato social mais amplo e o questionamento de valores tradicionais. A possibilidade real de construir carreira amplia os horizontes, antes circunscritos ao espaço privado, mas surgem novas exigências para conciliar essas diferentes esferas. O ideal que vincula trabalho e autonomia, na prática, não se dá sem custos. Assim, o conflito que permanece, embora sofra alterações, é aquele entre o real e o ideal. Maior autonomia feminina só tem sido possível com o acúmulo de atribuições. Nesse contexto, a separação pode agravar ainda mais as responsabilidades femininas, e talvez seja esse um dos motivos que ainda mantém o casamento entre os projetos femininos. A necessidade de conciliar esses campos de atuação não é vivida sem dificuldades pelas mulheres atuais, porém tais dificuldades não são sentidas como empecilho a essa conciliação, como pudemos observar entre as participantes do grupo mais jovem.

Não se pode perder de vista que, mesmo se afastando dos modelos oferecidos pelos pais, eles são importantes referências para o comportamento das gerações seguintes. Considerando as díades da mesma família, verifica-se que, mesmo havendo diferenciação entre mãe e filha, a mãe acaba sendo referência, mesmo que seja para não ser seguida. Várias participantes destacam o quanto a experiência da mãe em relação ao casamento foi importante para que pudessem traçar seus próprios caminhos.

É difícil falar em transmissão geracional direta, mas sem dúvida a observação da geração anterior, consideradas as mudanças contextuais, assegura que diversos elementos são absorvidos pelos filhos. Assim, a realidade social atual na qual a família se insere é marcada pela heterogeneidade, de forma que estão coexistindo modelos do passado e atuais, sendo impossível falar apenas em mudanças ou apenas em continuidades. Como assinala Rocha-Coutinho (2006: 100-101): "diferentemente do passado [...] estamos assistindo agora a um momento de indefinição 
e ausência de modelos fixos e imutáveis. Valores e padrões de comportamento tradicionais coexistem, muitas vezes em conflito, com novos valores e padrões de comportamento no interior das famílias".

Os resultados mostram que a vivência do cotidiano familiar e, sobretudo, do conjugal, nas últimas décadas, incorporou novas significações e práticas que se afastam, em certa medida, de concepçôes tradicionais. Maior escolarização e profissionalização feminina, e decorrências de tais processos, como maior participação na esfera pública, foram essenciais para essa ressignificação. Contudo, em grande parte, a identidade feminina e as relações de gênero ainda se veem assentadas em bases tradicionais e na articulação de passado e presente novas identidades têm sido engendradas.

\section{REFERÊNCIAS}

Abric, J. C. (2000). A abordagem estrutural das representaçōes sociais. In: Moreira, A. S. P. \& Oliveira, D. C. (Orgs.). Estudos interdisciplinares em representação social (pp.3946). Goiânia: AB.

Araújo, C. \& Scalon, C. (2005) Percepções e atitudes de mulheres e homens sobre conciliação entre família e trabalho pago no Brasil. In: Araújo, C. \& Scalon, C. (Orgs.). Gênero, trabalho e familia no Brasil (pp. 15-88). Rio de Janeiro: FGV.

Ariès, P. (1981). História social da criança e da família. São Paulo: LTC.

Assmar, E. M. L.; Ferreira, M.; Novaes, H. \& Tomaz, M. (2000). Premissas histórico-socioculturais sobre a família brasileira em função do sexo e da idade. Psicologia: Reflexão e Crítica, 13(1), 89-96.

Barbosa, P. Z. \& Rocha-Coutinho, M. L. (2007). Maternidade: novas possibilidades, antigas visōes. Psicologia Clínica, 19(1), 163-185.

Bassanezi, C. (2002). Mulheres dos anos dourados. In: Del Priore, M. (Org.) História das mulheres no Brasil (pp. 607-639). São Paulo: Contexto.

Benincá, C. R. S. \& Gomes, W. B. (1998). Relatos de mães sobre transformações familiares em três gerações. Estudos de Psicologia, 3(2), 177-205.

Brasileiro, R. F., Jablonski, B. \& Féres-Carneiro, T. (2002). Papéis de gênero, transição para a paternalidade e a questão da tradicionalização. Psico, 33(2), 289-310.

Bullington, J. \& Karlsson, G. (1984). Introduction to phenomenological psychological research. Scandinavian Journal of Psychology, 25, 51-63.

Costa, J. F. (1999). Ordem médica e norma familiar. Rio de Janeiro: Ediçōes Graal.

Coutinho, S. M. S. (2008). "A dona de tudo": o que é ser mulher, mãe e esposa de acordo com as representaçôes sociais de mulheres de duas geraçōes. (Tese de Doutorado. Programa de Pós-Graduação em Psicologia, UFES, Vitória). 
Del Priore, M. (2005). História do amor no Brasil. São Paulo: Contexto.

Dias, A. C. G. \& Lopes, R. C. S. (2003). Representações de maternidade de mães jovens e suas mães. Psicologia em Estudo, 8 (nº especial), 63-73.

Falcke, D. \& Wagner, A. (2005). A dinâmica familiar e o fenômeno da transgeracionalidade: definição de conceitos. In: Wagner, A. (Org.). Como se perpetua a família? A transmissão dos modelos familiares (pp. 25-46). Porto Alegre: EdiPUCRS.

Féres-Carneiro,T. (2001). Casamento contemporâneo: construção da identidade conjugal. In: Terezinha Féres-Carneiro, (Org.). Casamento e família: do social à clínica. Rio de Janeiro: NAU Editora.

Giddens, A. (1992). A transformação da intimidade. São Paulo: Unesp.

Grzybowski, L. S. (2002). Famílias monoparentais: mulheres divorciadas chefes de família. In. Wagner, A. (Org.). Família em cena: tramas, dramas e transformações (pp. 39-53). Petrópolis: Vozes.

Jablonski, B. (1998). Até que a vida nos separe: a crise do casamento contemporâneo. Rio de Janeiro: Agir.

Jablonski, B. (2001). Atitudes frente à crise do casamento. In: Féres-Carneiro, T. (Org.). Casamento e família: do social à clínica (pp. 81-95). Rio de Janeiro: Nau.

Jodelet, D. (2001). Representações sociais: um domínio em expansão. In: Jodelet, D. (Org.). As representações sociais (pp. 17-44). Rio de Janeiro: EdUERJ.

Kronberger, N. \& Wagner, W. (2002). Palavras-chave em contexto: análise estatística de textos. In: Bauer, M. B., Gaskell, G. (Orgs.). Pesquisa qualitativa com texto, imagem e som - um manual prático (pp. 416-441). Petrópolis: Vozes.

Lins de Barros, M. (2006). Família e geraçôes. Rio de Janeiro: FGV.

Lisboa, A. V., Féres-Carneiro, T. \& Jablonski, B. (2007). Transmissão intergeracional da cultura: um estudo sobre uma família mineira. Psicologia em Estudo, 12(1), 51-59.

Marcová, I. (2006). Dialogicidade e representaçôes sociais: as dinâmicas da mente. Petrópolis: Vozes.

Menandro, M. C. S. (2004). Gente jovem reunida: um estudo de representaçôes sociais da adolescêncialjuventude a partir de textos jornalisticos (1968/1974-1996/2002). (Tese de Doutorado. Programa de Pós-Graduação em Psicologia, UFES, Vitória).

Moscovici, S. (1978). Representação social da psicanálise. Rio de Janeiro: Zahar.

Nader, M. B. (2001). Mulher: do destino biológico ao destino social. Vitória: Edufes.

Queiroz, A. B. A. (2002). O ser mulher e a infertilidade: um estudo de representaçôes sociais. (Tese de Doutorado. UFRJ, Escola de Enfermagem, Rio de Janeiro).

Quintas, F. (2000). A mulher e a familia no final do século XX. Recife: FJN, Massangana.

Rêgo, N. N., Bastos, A. C. S. \& Alcântara, M. A. R. (2002). As mulheres da família: mundos partilhados, mundos em conflito. Paidéia, 12(22), 27-37. 
Reinert, M. (1990). Alceste - une méthodologie d'analyse des données textuelles et une application: Aurélia de Gérard de Nerval. Bulletin de Méthodologie Sociologique, 26, 24-54.

Relvas, A. P. (2002). A mulher na família: “em torno dela”. In: Relvas, A. P. \& Alarcão, M. Novas formas de familia (pp. 299-340). Coimbra: Quarteto.

Rocha-Coutinho, M. L. (1994). Tecendo por trás dos panos: a mulher brasileira nas relaçôes familiares. Rio de Janeiro: Rocco.

Rocha-Coutinho, M. L. (2003). O papel de homens e mulheres na família: podemos falar em reestruturação? Psicologia Clínica, 15(2), 93-107.

Rocha-Coutinho, M. L. (2006). Transmissão geracional e família na contemporaneidade. In: Lins de Barros, M. (Org.). Família e gerações (pp. 91-106). Rio de Janeiro: FGV.

Rouquette, M.-L. (2000). Représentations et pratiques sociales: une analyse théorique. In: Garnier, C. \& Rouquette, M.-L. (Eds). Représentations sociales et éducation, 133-142. Montréal: Editions Nouvelles.

Teixeira, M. C. V., Schulze, C. M. N. \& Camargo, B. V. (2002). Representações sociais sobre a saúde na velhice: um diagnóstico psicossocial na Rede Básica de Saúde. Estudos de Psicologia, 7, 351-359.

Trindade, Z. A. (1991). As representações sociais da maternidade e da paternidade: implicações no processo de aconselhamento genético. (Tese de Doutorado. Instituto de Psicologia, USP, São Paulo).

Trindade, Z. A., Menandro, M. C. S. \& Gianórdoli-Nascimento, I. F. (2007). Organização e interpretação de entrevistas: uma proposta de procedimento a partir da perspectiva fenomenológica. In. Rodrigues, M. M. P. \& Menandro, P. R. M. (Orgs.). Lógicas metodológicas: trajetos de pesquisa em psicologia (pp. 71-92). Vitória: UFES / GM Gráfica Editora.

Unbehaum, S. G. (2001). A desigualdade de gênero nas relações parentais: o exemplo da custódia dos filhos. In: Arrilha, M., Unbehaum, S. G. \& Medrado, B. (Orgs.). Homens e masculinidades: outras palavras (pp. 163-184). São Paulo: Ecos / Editora 34.

Vaitsman, J. (1994). Flexiveis e plurais: identidade, casamento e família em circunstâncias pós-modernas. Rio de Janeiro: Rocco.

Vitale, M. A. F. (2002). Socialização e família: uma análise intergeracional. In: Brant de Carvalho, M. C. (Org.). A familia contemporânea em debate (pp. 89-96). São Paulo: EDUC/ Cortez.

Zechlinski, B. P. (2006). Imagens do casamento e do amor em Nelson Rodrigues: um estudo das representaçôes de gênero na literatura publicada em jornal entre 1944 e 1961. (Dissertação de Mestrado. Programa de Pós-Graduação em História. UFPR: Curitiba). 


\section{Anexo}

Quadro 1: Caracterização das participantes

\begin{tabular}{|c|c|c|c|c|c|c|c|c|}
\hline $\begin{array}{l}\text { Participante } \\
\text { / Geração }\end{array}$ & Idade & Escolaridade & $\begin{array}{c}\text { Estado } \\
\text { civil }\end{array}$ & $\begin{array}{c}\text { Tempo } \\
\text { de } \\
\text { uniáo } \\
\text { (anos) }\end{array}$ & $\begin{array}{l}\text { No de } \\
\text { Filhos }\end{array}$ & $\begin{array}{c}\text { Atividade } \\
\text { profissional } \\
\text { (após } \\
\text { casamento) }\end{array}$ & Religiāo & $\begin{array}{c}\text { Nível } \\
\text { econômico } \\
\text { (quando } \\
\text { filhos } \\
\text { eram } \\
\text { pequenos) }\end{array}$ \\
\hline Ana / $1^{a} G$ & 74 & $\begin{array}{c}1^{\circ} \text { grau } \\
\text { incomp. }\end{array}$ & casada & 53 & 9 & não & católica & médio \\
\hline Alice / 2a $\mathrm{G}$ & 44 & $3^{\circ}$ grau & casada & 17 & 2 & $\operatorname{sim}$ & católica & médio \\
\hline $\begin{array}{l}\text { Berenice / } \\
1^{\text {a } G}\end{array}$ & 65 & $\begin{array}{l}1^{\circ} \text { grau } \\
\text { incomp. }\end{array}$ & viúva & 31 & $\begin{array}{c}3(1 \\
\text { falecido) }\end{array}$ & não & católica & médio \\
\hline $\begin{array}{l}\text { Bárbara / } \\
2^{\text {a } G}\end{array}$ & 38 & $3^{\circ}$ grau & casada & 13 & 1 & $\operatorname{sim}$ & cardecista & médio \\
\hline Célia / 1 1 a & 60 & $2^{\circ} \mathrm{grau}$ & casada & 40 & 4 & $\operatorname{sim}$ & católica & médio \\
\hline Clara / 2a G & 37 & $2^{\circ}$ grau & casada & 15 & 2 & $\operatorname{sim}$ & católica & médio \\
\hline Dalva / 1 $1^{\mathrm{a}} \mathrm{G}$ & 62 & $\begin{array}{l}1^{\circ} \text { grau } \\
\text { incomp. }\end{array}$ & viúva & 31 & 3 & não & católica & baixo \\
\hline Diana / 2a $G$ & 37 & $2^{\circ} \mathrm{grau}$ & casada & 13 & 2 & $\operatorname{sim}$ & católica & médio \\
\hline Eva / $1^{\text {a }} \mathrm{G}$ & 72 & $\begin{array}{l}1^{\circ} \text { grau } \\
\text { incomp. }\end{array}$ & divorciada & 13 & $\begin{array}{c}6(2 \\
\text { falecidos })\end{array}$ & não & católica & baixo \\
\hline Elisa / 2a $\mathrm{G}$ & 45 & $\begin{array}{l}3^{\circ} \text { grau em } \\
\text { curso }\end{array}$ & casada & 20 & 1 & $\operatorname{sim}$ & católica & médio \\
\hline $\begin{array}{l}\text { Fátima / } \\
1^{\mathrm{a}} \mathrm{G}\end{array}$ & 62 & $\begin{array}{l}1^{\circ} \text { grau } \\
\text { incomp. }\end{array}$ & divorciada & 15 & 3 & não & evangélica & baixo \\
\hline $\begin{array}{l}\text { Fernanda / } \\
2^{\text {a }} \mathrm{G}\end{array}$ & 39 & $\begin{array}{l}3 \text { o grau } \\
\text { incomp. }\end{array}$ & casada & 18 & 2 & $\operatorname{sim}$ & evangélica & médio \\
\hline $\begin{array}{l}\text { Glória / } \\
1^{\text {a }} \mathrm{G}\end{array}$ & 61 & $2^{\circ} \mathrm{grau}$ & viúva & 24 & 4 & $\operatorname{sim}$ & católica & baixo \\
\hline $\begin{array}{l}\text { Giovana / } \\
2^{\text {a } G}\end{array}$ & 43 & $3^{\circ}$ grau & casada & 12 & 1 & $\operatorname{sim}$ & evangélica & médio \\
\hline Hilda / 1 $1^{\text {a } G}$ & 60 & $\begin{array}{l}1^{\circ} \text { grau } \\
\text { incomp. }\end{array}$ & casada & 40 & 4 & não & evangélica & médio \\
\hline $\begin{array}{l}\text { Helena / } \\
2^{\text {a } G}\end{array}$ & 36 & $3^{\circ}$ grau & casada & 19 & 2 & $\operatorname{sim}$ & evangélica & médio \\
\hline Ivone / $1^{\mathrm{a}} \mathrm{G}$ & 60 & $3^{\circ}$ grau & casada & 41 & $\begin{array}{c}5(1 \\
\text { adotiva })\end{array}$ & $\operatorname{sim}$ & evangélica & médio \\
\hline Isa / 2a $G$ & 34 & $3^{\circ}$ grau & casada & 12 & 2 & $\operatorname{sim}$ & evangélica & médio \\
\hline Joana / $1^{\mathrm{a}} \mathrm{G}$ & 70 & $\begin{array}{l}1^{\circ} \text { grau } \\
\text { incomp. }\end{array}$ & casada & 50 & 6 & não & evangélica & baixo \\
\hline
\end{tabular}




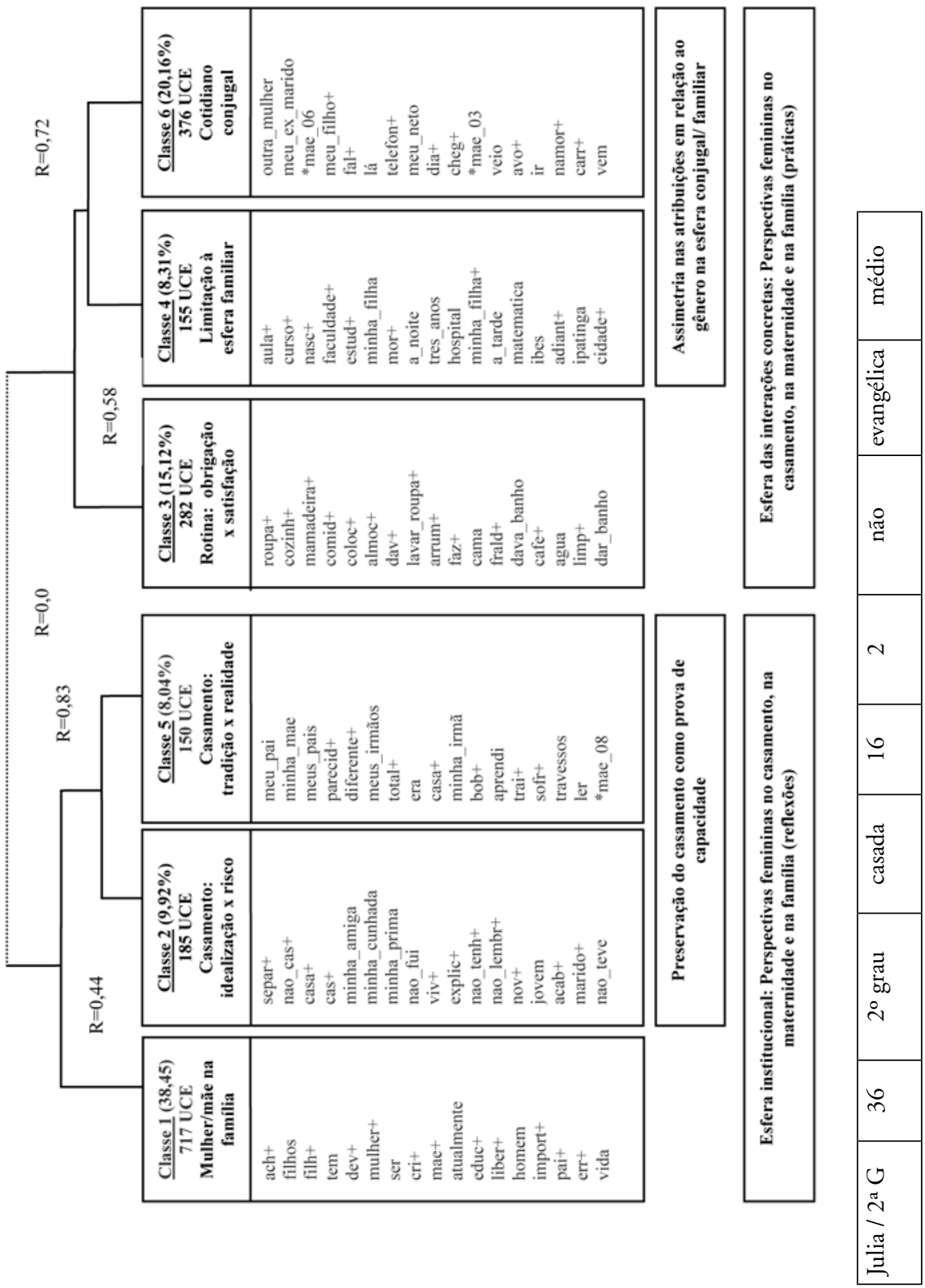




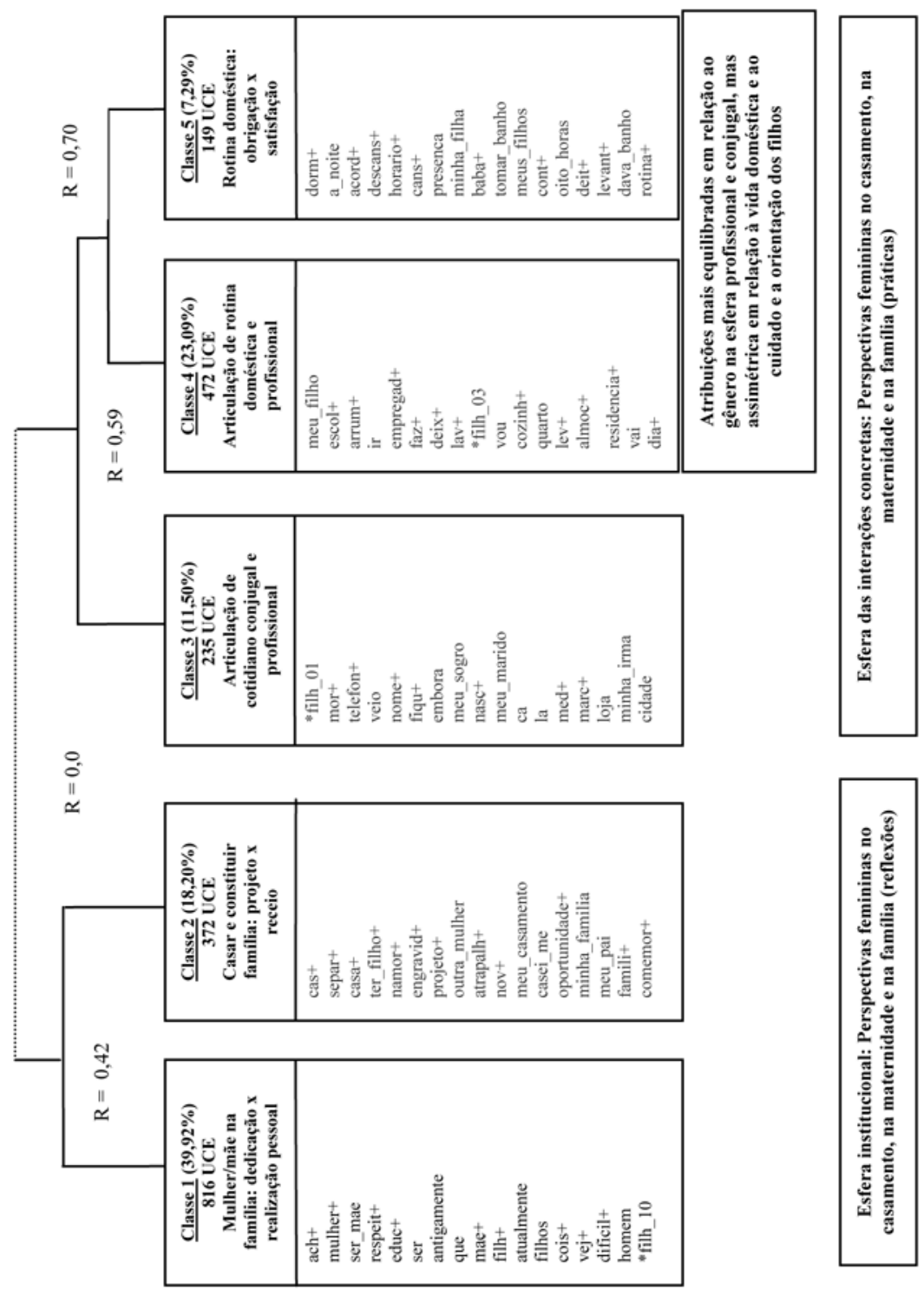

Figura 1 - Dendrograma das classes - RS de mulheres 